\title{
ATIVIDADES LÚDICAS COMO ESTRATÉGIA PARA A PROMOÇÃO DA SAUDE BUCAL INFANTIL
}

\section{Ana Lídia Soares Cota}

Docente titular do curso de Odontologia e Docente colaboradora do Programa de Pós-graduação (Mestrado) em Sociedade, Tecnologias e Políticas Públicas do Centro Universitário Tiradentes, Maceió (AL), Brasil; Doutora em Ciências Odontológicas Aplicadas pela Faculdade de Odontologia de Bauru (USP), Brasil.

E-mail: ana.cota@uol.com.br

\section{Bárbara Jéssica de Assunção Costa}

Discente do curso de Odontologia do Centro Universitário Tiradentes, Maceió (AL), Brasil.
RESUMO: As ações de promoção de saúde bucal, particularmente as direcionadas ao público infantil, devem ser acionadas por meio de ferramentas que tornem o processo de aprendizagem mais dinâmico e de fácil compreensão. Assim, este trabalho visa relatar a importância da utilização do lúdico como estratégia para promoção da saúde bucal infantil. A escolha de um recurso ou da associação de diferentes estratégias lúdicas, como jogos educativos, teatro, música e exposição de macromodelos, deve ser feita de forma racional e considerando não apenas as preferências e habilidades do profissional, mas, sobretudo, a adequação dos temas, regras e ações da atividade à idade e ao nível cognitivo e motor de desenvolvimento da criança. $\mathrm{O}$ importante é as informações serem reforçadas e transmitidas de forma simples e envolvente para que os participantes tenham o raciocínio e a criatividade estimulados e a oportunidade de interagir de modo harmoniosa, inclusivo e feliz.

PALAVRAS-CHAVE: Ludoterapia; Promoção da Saúde; Saúde Bucal.

\section{PLAYFUL ACTIVITIES AS A STRATEGY FOR PROMOTION OF CHILDREN'S ORAL HEALTH}

ABSTRACT: Oral health promotion actions, especially those aimed at children, should be driven by tools that make the learning process more dynamic and easy to understand. Thus, this paper aims to report the importance to use the playful as a strategy for promotion of children's oral health. The choice of a resource or the association of different playful strategies, like educational games, theatre, music and macro models show, should be made rationally and considering not only skills and preferences of the professional, but, mainly, the suitability of topics, rules and actions of the activity to the age and to the cognitive and motor levels of the child development. The information should be reinforced and transmitted in a simple and engaging way, so that the participants have the reasoning and creativity stimulated and the opportunity to interact in a harmonious, inclusive and happy way.

KEY WORD: Play Therapy; Health Promotion; Oral Health.

\section{INTRODUÇÃO}

Considerando a história natural da cárie dentária, a doença pode ser considerada uma patologia passível de ser prevenida, controlada ou até mesmo revertida. Entretanto, ainda se destaca como a doença crônica mais comum na infância, consistindo em um grande problema 
para a saúde pública mundial, uma vez que, dependendo de seu estágio, pode causar de episódios de dor até a perda de elementos dentários. Tais consequências e outras possíveis sequelas da doença tendem a afetar as crianças física e psicologicamente, comprometendo o crescimento e desenvolvimento infantil e prejudicando sua fala, mastigação, estética e respiração (LOSSO et al., 2009).

A promoção da saúde bucal, com enfoque na prevenção da cárie dentária, deve ser inserida na rotina das crianças de forma precoce, oportunizando a aquisição de conhecimentos e a aquisição de hábitos saudáveis que serão prolongados ao longo da sua vida (VENÂNCIO, 2011). Dentro desse contexto, a educação tem sido relacionada como uma prática viabilizadora da saúde bucal (FADEL; BORDIN; LANGOSKI, 2013).

A educação em saúde implica no conhecimento e na conscientização das pessoas aliado ao desenvolvimento das habilidades necessárias para alcançar a saúde bucal é, portanto, focada em oportunidades de aprendizagem, podendo ser desenvolvida em uma enorme diversidade de espaços sociais, grupos populacionais e diferentes atividades (MALLMANN et al., 2015).

$\mathrm{Na}$ odontologia, a educação tem grande importância para a promoção da saúde bucal, principalmente no público infantil. Assim, um dos recursos utilizados para a prevenção da cárie dentária é o desenvolvimento de atividades lúdicas para facilitar a aprendizagem e a construção do conhecimento, que tem por finalidade a melhoria da qualidade de vida e saúde do paciente (GARCIA et al., 2009; SANTOS; GARBIN; GARBIN, 2012; FILHO et al., 2014). De acordo com Nakahara et al. (2012), brincar está intimamente ligado à infância e ao desenvolvimento das crianças, sendo uma das maneiras mais eficazes para envolvê-las no processo educativo, e por consequência, na promoção da saúde.

Sabendo que o controle da cárie dentária está diretamente relacionado com a aquisição de bons hábitos alimentares e de higiene bucal, torna-se importante desenvolver atividades que estejam relacionadas com suas necessidades e que, ao mesmo tempo, causem um impacto motivacional nos indivíduos (MORAES et al., 2011). Nesse panorama, o lúdico favorece um aprendizado efetivo, pois enfatiza um determinado assunto, gerando conhecimento para todos os participantes de uma atividade proposta (COSCRATO; PINA; MELLO, 2010).

Dessa forma, o objetivo do presente trabalho é, por meio de uma revisão narrativa, relatar a importância da utilização do lúdico como estratégia para promoção da saúde bucal infantil, destacando algumas atividades que poderão ser desenvolvidas pelos cirurgiões-dentistas no processo educativo.

\section{REVISÃO DE LITERATURA}

O termo lúdico tem origem da palavra latina ludus e significa jogo, brinquedo (TRISTÃO, 2010). Os estudos literários iniciais apontam que o lúdico esteve presente em todas as épocas da história da humanidade. $\mathrm{Na}$ antiguidade já se falava no valor das brincadeiras e jogos, como forma de aprendizado. A partir dos estudos realizados ao longo dos anos pode-se afirmar que as atividades lúdicas têm grande importância para 0 desenvolvimento global da criança (CORDAZZO, 2007).

Atualmente, é indiscutível a importância do lúdico para o ser humano. Brincar, jogar, desenhar, dramatizar, contar histórias não se limita, contudo, a momentos prazerosos. Algumas vezes, muitas dificuldades, a maioria inconsciente, podem expressarse com o uso desses recursos. Tais instrumentos, por revelarem dimensões psíquicas profundas, podem facilitar, portanto, intervenções em indivíduos com fobia, dor e em outras situações especiais (BARRETO, 2013).

Todo processo educativo pode ser iniciado através de brincadeiras e atividades lúdicas, ressaltando que a utilização de recursos lúdicos, unidos às técnicas convencionais de educação transformam o processo de aprendizagem em um processo ativo, no qual a informação transmitida é colocada em prática com o auxílio de divertimento, motivação e reforço do aprendizado (MORAES et al., 2011).

Os recursos lúdicos podem atuar como mediadores do processo ensino-aprendizagem, tornando-se um método alternativo para auxiliar esse processo (COSCRATO; PINA; MELLO, 2010). Por meio da brincadeira, a criança conhece o mundo que a rodeia, constrói significados, assimila os papéis sociais, 
o entendimento das relações afetivas e a construção do conhecimento (FIGUEIRA; LEITE, 2008).

A utilização das brincadeiras vem ganhando espaço nas ações em saúde. O brincar proporciona a oportunidade de escolha pela criança, bem como uma linguagem adequada de acordo com sua idade, permitindo que ela coloque-se como agente ativo do seu tratamento (LIRA; RUBIO, 2014). Na odontologia, o lúdico tem sido utilizado como facilitador de uma dinâmica de interações que (re)significam o modelo tradicional de intervenção e cuidados no âmbito de sua atuação (OLIVEIRA, 2014).

A saúde bucal é fundamental para saúde geral do indivíduo e desempenha papel importante para realizar funções como mastigação, deglutição e fonação. Dessa forma, a educação em saúde bucal permite adquirir conhecimentos e desenvolvimento de habilidades que possibilite a formação ou mudanças de atitudes pelo individuo em relação a sua saúde (SANTOS; GARBIN; GARBIN, 2012).

$\mathrm{Na}$ odontologia atual, o desafio é intervir de forma educativa no público infantil através de ações que contribuam para a aquisição de informações necessárias no desenvolvimento de hábitos saudáveis. Os profissionais da área odontológica podem atuar na formulação de políticas públicas com finalidade de promover a saúde e prevenir doenças bucais, como a cárie dentária (BEZERRA; GOMES, 2010).

Estratégias educativas para a promoção de saúde são capazes de educar e gerar motivação (OLIVEIRA et al., 2012). Mas para que a educação e motivação produzam resultados desejados, o profissional deve utilizar métodos apropriados, compatíveis com o público alvo, principalmente quando se trabalha com a população infantil (GARCIA et al., 2009).

A seguir, serão elencadas algumas atividades lúdicas com potencial de serem inseridas nas práticas odontológicas educativo-preventivas.

\subsection{JOGOS EDUCATIVOS}

Os jogos como ferramenta pedagógica aparecem como uma atividade lúdica bastante utilizada, pois têm a finalidade de transmitir conhecimentos sobre temas específicos, divertir e motivar os participantes. Seu uso já provou ser eficaz em várias áreas do saber, pois proporcionam, junto à interatividade, novas formas de aplicação do conhecimento através da proposição de desafios (RODRIGUES, 2014).

Um ponto importante sobre os jogos é a maneira como influenciam o desenvolvimento da agilidade, concentração e do raciocínio, contribuindo para que haja uma evolução intelectual do participante, particularmente do público infantil. Para isso, são necessárias ações como pensar, tomar decisões, criar, inventar, aprender a arriscar e experimentar, estabelecendo um bom comportamento em grupo e também nas relações pessoais com o meio cultural no qual o sujeito está inserido (BATISTA; DIAS, 2012). Os jogos são atividades de ocupação voluntária que envolvem ações criativas e, assim, auxiliam no processo de crescimento e desenvolvimento infantil (OLIVEIRA, 2011).

A aquisição de conhecimento mediadas pelos jogos podem se constituir no primeiro passo para a geração de novas atitudes de prevenção, à medida que suas ações estejam associadas a políticas socioeconômicas e ambientais que favoreçam esta mudança (TOSCANI et al., 2007).

Mialhe et al. (2008) verificaram que, de modo geral, a utilização de diversos tipos de jogos, como os de tabuleiro ou de memória e caça palavras, são capazes de transmitir bons conhecimentos sobre os conceitos de saúde bucal às crianças. Alguns levam o conhecimento de forma direta através de perguntas e respostas, enquanto outros agem de forma indireta, despertando uma curiosidade sobre algo desconhecido, ou muito pouco conhecido.

Nos dias atuais não se pode deixar de mencionar o uso da computação, por meio dos jogos digitais, como aliada no processo ensino-aprendizagem. Dotta, Campos e Garcia (2012) afirmam que esse tipo de interação pode ser um excelente recurso para a educação e motivação de crianças com vistas à promoção da saúde bucal. Entretanto, Vasconcelos Filho (2014), destaca que a maioria dos jogos (aplicativos comerciais) existentes no mercado só visa entreter as crianças e é de complexa interação, fazendo com que elas atuem como dentistas, removendo placas bacterianas, obturando cáries e extraindo dentes. Adicionalmente, Morais et al. (2011) 
alertam que os serious games limitam-se a quatro temas principais - conceitos básicos de saúde bucal, higiene bucal de crianças e adultos, ida ao dentista e treinamento de profissionais - e que restringem-se à autoavaliação do jogador por meio da sua educação ou informação, ou seja, os conteúdos apreendidos por meio destas ferramentas devem ser executados pelo jogador em si próprio. Porém, quando as informações abordadas referem-se à primeira infância, esta perspectiva muda, pois o público-alvo não será os bebês, e sim as mães.

\subsection{TEATRO DE FANTOCHES/ATORES}

No ensino lúdico, o teatro pode ser uma excelente abordagem nas ações educativas em saúde, dinamizando o modo de ensinar sobre hábitos saudáveis e estimulando a participação e interação da criança (LUCHETTI; MOREALE; PARRO, 2011). O teatro infantil pode ser visto como um meio através do qual se transmite uma mensagem. Seu enredo é produzido visando determinado foco educacional (PEREIRA; TÉRAN, 2007).

Sabe-se que, de forma criativa, interativa e divertida, atividades lúdicas, como o teatro, incentivam o processo ensino-aprendizagem e despertam um maior interesse em aprender o que está sendo transmitido nas ações educativas (SOUZA et al., 2010). Através do teatro, o processo de aprendizagem torna-se mais prazeroso e participativo, além de ser uma forma de entretenimento e de educação, pois pode auxiliar no desenvolvimento do trabalho em grupo, ajudar a superar a timidez, desenvolver a imaginação, memorização e o vocabulário. As atividades que envolvem teatro são capazes de proporcionar novas experiências e, dessa forma, contribuir para o crescimento integral da criança (SANTOS; SANTOS, 2012).

\subsection{MÚSICAS}

Ainda no contexto de educação infantil, a música, sendo um meio de expressão, pode ser usada como um elemento que propicia momentos lúdicos. $\mathrm{Na}$ educação, a música tem a finalidade de ampliar e facilitar a aprendizagem, pois ensina o indivíduo a ouvir e a escutar de maneira ativa e refletida (ONGARO; SILVA; RICCI, 2007).
Atividades com música são capazes de promover o desenvolvimento infantil, pois permitem que a criança utilize instrumentos verbais que podem ser transferidos para outras circunstâncias, uma vez que a qualidade do pensamento depende das associações e generalizações que ela aprende a estabelecer (SCHERER, 2013). A ludicidade da música contribui positivamente no processo de assimilação do conteúdo, podendo ser percebido pela participação e grande interesse dos participantes nas atividades (SOUZA et al. 2015).

$\mathrm{Na}$ odontologia, pode-se utilizar as músicas ou paródias musicais para motivar, reforçar e explicar às crianças as várias etapas do atendimento odontológico e da prevenção ao tratamento propriamente dito. Letras com conceitos relacionados à odontologia e associadas a ritmos cativantes podem tornar o momento da escovação mais divertido, possibilitando uma maior retenção de informação de forma descontraída pela criança (CORRÊA, 2010). Além disso, a música também pode atuar como uma forma de redução do medo e ansiedade no tratamento odontológico (AGUIAR; SANTOS; SILVA, 2010; RANGEL; SILVA, 2016).

Um exemplo positivo da utilização da música como metodologia pedagógica é relatado por Souza et al (2015), onde os autores, por intermédio do Projeto Cultura Bucal, difundiram informação e conhecimento em saúde bucal para crianças e adolescentes participantes de uma orquestra de sopro, melhorando a qualidade de vida dos participantes. Entretanto, para lograr êxito ao utilizar músicas relacionadas à odontologia, é necessário que os conceitos sobre a doença cárie e sua prevenção sejam transmitidos de forma divertida, envolvente e com linguagem própria e acessível às crianças (MIELE et al., 2000).

\subsection{EXPOSIÇÃO DE MACROMODELOS}

Outro recurso frequentemente utilizado para auxiliar as atividades educativas em odontologia é a exposição de macromodelos para abordar alguns temas relacionados à saúde bucal como, por exemplo, a escovação dentária. A interação com os macromodelos desperta a curiosidade e interatividade entre as crianças, facilitando a compreensão do que está sendo exposto, 
além de gerar motivação e interesse pela manutenção de sua saúde (ARAUJO; CARVALHO, 2012; SOUZA et al., 2015).

SILVEIRA et al. (2015) destacam que a orientação de higiene bucal envolvendo recursos como macromodelos torna-se efetiva no estabelecimento de uma rotina de higiene adequada, agregando assim o conhecimento sobre o assunto e resultando em melhora nos índices de saúde bucal dos pacientes.

Segundo Makuch e Reschke (2001), é evidente que a utilização de atividades lúdicas, como jogos e teatro de fantoches, é mais efetiva do que uma simples apresentação didática de práticas em saúde bucal. Entretanto, Antônio et al (2015) perceberam que as atividades educativas lúdicas (teatro, jogos em formato de gincana, história em quadrinhos e palestra com o uso de macromodelos), de maneira geral, não influenciam no conhecimento adquirido e que esses métodos podem ser considerados materiais de apoio e, como tais, devem ser explorados e trabalhados em conjunto com os métodos educativos tradicionais.

Assim, cabe ao profissional ter em mente que ao trabalhar ludicamente não se está abandonando a seriedade e a importância dos conteúdos a serem apresentados às crianças, pois as atividades lúdicas são indispensáveis para o seu desenvolvimento e para a apreensão dos conhecimentos, uma vez que possibilitam o desenvolvimento da percepção, da imaginação, da fantasia e dos sentimentos (DALLABONA; MENDES, 2004).

\section{CONSIDERAÇÕES FINAIS}

É inquestionável o papel da ludicidade enquanto método educativo para promoção da saúde bucal infantil, pois as atividades lúdicas, quando sistematicamente planejadas e corretamente desenvolvidas, funcionam atraindo a atenção e gerando a motivação da criança no processo de aprendizagem e estimulando a mudança ou adoção de comportamentos que possam melhorar a qualidade de vida do indivíduo.

A escolha pela utilização de um único recurso ou pela associação de diferentes estratégias lúdicas, como jogos educativos, teatro, música e exposição de macromodelos, deve ser feita de forma racional e considerando não apenas as preferências e habilidades do profissional, mas, sobretudo, a adequação dos temas, regras e ações da atividade à idade e ao nível cognitivo e motor de desenvolvimento da criança. O importante é que as informações sejam reforçadas e transmitidas de uma maneira simples e envolvente, de forma que os participantes tenham o raciocínio e a criatividade estimulados e a oportunidade de interagir de forma harmoniosa, inclusiva e feliz.

Diante do exposto, constata-se que a utilização do lúdico como uma das mais importantes ferramentas de aprendizagem na infância deve ser incentivada desde a etapa de formação acadêmica, principalmente, por meio da extensão universitária. Assim, espera-se que o presente trabalho oportunize aos cirurgiões-dentistas a compreensão do significado e da importância das atividades lúdicas na manutenção e promoção da saúde bucal infantil, procurando provocá-los para que insiram o brincar no processo educativo de seus pacientes.

\section{REFERÊNCIAS}

AGUIAR, S. M. H. C. Á.; SANTOS, M. J. P.; SILVA, V. C. A música associada às necessidades terapêuticas de Pacientes com Deficiência. Revista Ciência em Extensão, São Paulo, v. 6, n. 2, p. 123-131, 2010.

ANTÔNIO, L. P. et al. Avaliação de diferentes métodos educativos em saúde bucal em crianças na faixa etária de 7 a 10 anos de idade. Revista da Faculdade de Odontologia, Rio Grande do Sul, v. 20, n. 1, p. 52-58, 2015.

ARAUJO, A. G. DE; CARVALHO, W. S. DE. Avaliação da efetividade da higiene bucal das crianças do lar padre vita de Pindamonhangaba - sp. 2012. 26f. Tese (Graduação em Odontologia) - Faculdade de Pindamonhangaba, São Paulo, 2012.

BARRETO, R.A. O lúdico em odontopediatria: contribuições psicológicas. In: MARIA SALETE NAHÁS PIRES CORRÊA. Conduta Clínica e Psicológica na Odontopediatria. São Paulo: Santos, 2013. 
BATISTA, D.A.; DIAS, C.L. O processo de ensino e de aprendizagem através dos jogos educativos no ensino fundamental. Revista Colloquium Humanarum, São Paulo, vol. 9, n. Especial, p. 975-982, 2012.

BEZERRA, T.; GOMES, J. O lúdico e as atividades de educação em saúde bucal: um estudo de caso na unidade de saúde da família do km 06-Natal/ RN. Disponível $\quad$ em: $<$ http://congressos.ifal.edu.br/index. php/connepi/CONNEPI2010/paper/viewFile/309/220 > Acesso em: 24 jun. 2017.

CORDAZZO, S. T. D. et al. Perspectivas no estudo do brincar: um levantamento bibliográfico. Aletheia, Canoas, n. 26, p. 122-126, 2007.

CORRÊA, M.S.N.P. Odontopediatria na primeira infância. 3. ed. São Paulo: Santos, 2010.

COSCRATO, G.; PINA, J. C.; MELLO, D. F. Utilização de atividades lúdicas na educação em saúde: uma revisão integrativa da literatura. Revista Paulista de Enfermagem, São Paulo, v.23, n. 2, p.257-263, 2010.

DALLABONA, S.; MENDES, S. O lúdico na educação infantil: jogar, brincar, uma forma de educar. Revista de Divulgação Técnico Científica do Icpg, Santa Catarina, v. 1, n. 4 , p. 107-112, 2004.

DOTTA, E.; CAMPOS, J. A. D. B.; GARCIA, P. P. N. S. Elaboração de um jogo digital educacional sobre saúde bucal direcionado para a população infantil. Pesquisa Brasileira em Odontopediatria e Clínica Integrada, Paraíba, v. 12, n. 2, p. 209-215, 2012.

FADEL, C.B.; BORDIN, D.; LANGOSKI, J.E. A educação como prática viabilizadora da saúde bucal. Journal of the Health Sciences Institute, UNIP, São Paulo, v.31, n. 2, p.136-140, 2013.

FIGUEIRA, T.R; LEITE, I.C.G. Percepções, conhecimentos e práticas em saúde bucal de escolares. Revista Gaúcha de Odontologia, São Paulo, v.56, n. 1, p.27-32. 2008.

GARCIA, P. P. N. S. et al. Educação em saúde: Efeito de um método de auto-instruçáo sobre os níveis de higiene oral em escolares. Pesquisa Brasileira em Odontopediatria e Clinica Integrada, Paraíba, v. 9, n. 3, p. 333-337, 2009.
LIRA, N. A. B.; RUBIO, J. A. S. A importância da psicomotricidade na educação infantil. Revista Eletrônica Saberes da Educação, São Paulo, v. 5, n. 1, p. 1-22, 2014.

LUCHETTI, A.; MOREALE, V.; PARRO, M. C. Educação em saúde: uma experiência com teatro de fantoches no ensino nutricional de escolares. CuidArte Enfermagem, São Paulo, v. 5, n. 2, p. 97-103, 2011.

LOSSO, E.M et al. Cárie precoce e severa na infância: uma abordagem integral. Jornal de Pediatria, Rio de Janeiro, v.85, n.4, 2009.

MAKUCH, A.; RESCHKE, K. Playing games in promoting childhood dental health. Patient Education and Counseling, Germany, v. 43, n. 1, p. 105-110, 2001.

MALLMANN, D. G. et al. Educação em saúde como principal alternativa para promover a saúde do idoso. Ciência \& Saúde Coletiva, Rio de Janeiro, v. 20, n. 6, p. 1763-1772, 2015.

MIALHE, F.L, GONÇALO, C.S., MORANO JÚNIOR, M. Jogos em odontologia: avaliação dos trabalhos desenvolvidos por escolares do ensino fundamental. Revista UNINGÁ, Paraná, n.16, p.13-25, 2008.

MIELE, G. M. S. et al. Música e motivação na odontopediatria. Jornal Brasileiro de Odontopediatria e Odontologia do Bebê, Curitiba, v. 3, n. 15, p. 414-423, 2000 .

MORAIS, A. M.; MACHADO, L. S.; VALENÇA, A. M. G. Planejamento de um Serious Games Voltado para Saúde Bucal em Bebês. Revista de Informática Teórica e Aplicada, Rio Grande do Sul, v. 18, n. 1, p. 158-175, 2011.

MORAES, K.R et al. Motivação de higiene dental utilizando brinquedos com temas odontológicos. Revista ConScientia e Saúde, São Paulo, v.10, n. 4, p.723-728. 2011.

NAKAHARA, M. M. et al. A utilização do lúdico na prevenção de acidentes na infância. HU Revista, Minas Gerais, v. 38, n. 3, p. 203-206, 2012. 
OLIVEIRA, J.C.C. Atividades lúdicas na odontopediatria: uma breve revisão da literatura. Revista Brasileira de Odontologia, Rio de Janeiro, v.71, n.1, p.103-107, 2014.

OLIVEIRA, M. F. et al. Motivação no controle do biofilme dental e o aprendizado em relação à saúde bucal em escolares. Publicatio UEPG: Ciências Biológicas e da Saúde, Paraná, v. 18, n. 2, p. 115-120, 2012.

OLIVEIRA, T.F. et al. Educação e controle da esquistossomose em Sumidouro (RJ, Brasil): avaliação de um jogo no contexto escolar. Revista Brasileira de Pesquisa em Educação em Ciências, São Paulo, v.8, n.3, 2011.

ONGARO, C.F.; SILVA, C.S.; RICCI, S. M. A importância da música na aprendizagem. UNIMEO/CTESOP, 2006.

PEREIRA, E.C.; TERÁN, A. F. As atividades lúdicas como estratégias metodológicas no ensino de hábitos higiênicos. Resultados das Pesquisas de Iniciação Científica da Escola Normal Superior - PROFIC 2006 - 2007, Manaus, p. 67-69, 2007.

RANGEL, T.; SILVA, A. Efeito da música instrumental no comportamento de bebês durante o tratamento odontológico Instrumental music effect in babies behavior during dental treatment. ClipeOdonto, São Paulo, v. 8, n. 1, p. 22-27, 2016.

RODRIGUES, M.H. Criação, desenvolvimento e aplicação de Serious game educativo para prevenção em saúde bucal infantil: "Caí, Perdi um Dente...E Daí?". 2014.153 f. Dissertação (Mestrado em Ciências Odontológicas) - Universidade de São Paulo, São Paulo. 2014.

SANTOS, A.; SANTOS, A. O teatro e suas contribuições para educação infantil na escola pública. In: ENDIPE ENCONTRO NACIONAL DE DIDÁTICA E PRÁTICAS DE ENSINO - UNICAMP, 16., 2012, São Paulo. Anais... São Paulo: ENDIPE, 2012. p. 5452-5463.

SANTOS, K. T.; GARBIN, A.J. I; GARBIN, C. A. S. Saúde bucal nas escolas: relato de experiência. Revista Ciência em Extensão, São Paulo, v. 8, n. 1, p. 161-169, 2012.
SCHERER, C. A. Educação musical: contribuições para o desenvolvimento do pensamento infantil. Nuances: estudos sobre Educação, São Paulo, v. 24, n. 1, p. 163182, 2013.

SILVEIRA, E. R. et al. Educação em saúde bucal direcionada aos deficientes visuais. Revista Brasileira de Educação Especial, São Paulo, v. 21, n. 2, p. 289-298, 2015.

SOUZA, H. et al. Cultura bucal: transformando odontologia em música oral. Raízes e Rumos, Rio de Janeiro, v. 3, n. 1, p. 131-142, 2015.

TOSCANI, N. V. et al. Desenvolvimento e análise de jogo educativo para crianças visando à prevenção de doenças parasitológicas. Revista Interface- Saúde, Educação, Comunicação, São Paulo, v.11, n. 22, p.281-294, 2007.

TRISTÃO, M. B. O lúdico na prática docente. 2010. $39 f$. Tese (Graduação em Pedagogia) - Universidade Federal Do Rio Grande Do Sul, Rio Grande do Sul, 2010.

VASCONCELOS FILHO, J.E. et al. Um jogo sério de apoio ao tratamento odontológico de crianças especiais. In: SIMPÓSIO BRASILEIRO DE GAMES E ENTRETENIMENTO DIGITAL, 13, 2014, Rio Grande do Sul. - Proceedings of SBGames... Rio Grande do Sul: SBC, 2014, p. 626-628.

VENÂNCIO, D. R. et al. Promoção da saúde bucal: desenvolvendo material lúdico para crianças na faixa etária pré-escolar. Journal of the Health Sciences Institute, São Paulo, v.29, n.3, p.153-156, 2011.

Recebido em: Aceito em: 